\title{
Prevalence and genetic diversity of endosymbiotic bacteria infecting cassava whiteflies in Africa
}

\author{
Saptarshi Ghosh, Sophie Bouvaine and MN Maruthi ${ }^{*}$
}

\begin{abstract}
Background: Cassava provides over half of the dietary requirement for more than 200 million poor in Africa. In recent years, cassava has been affected by an epidemic of a virus disease called cassava brown streak disease (CBSD) that is spreading in much of eastern and central Africa, affecting food security and the economic development of the poor. The viruses that cause CBSD are transmitted by the insect vector whitefly (Bemisia tabaci), which have increased to very high numbers in some African countries. Strains of endosymbiotic bacteria infecting whiteflies have been reported to interact specifically with different whitefly populations with varied effects on its host biology and efficiency of virus transmission. The main aim of this study was therefore to investigate the prevalence and diversity of the secondary endosymbiotic bacteria infecting cassava whiteflies with a view to better understand their role on insect population dynamics and virus disease epidemics.
\end{abstract}

Results: The genetic diversity of field-collected whitefly from Tanzania, Malawi, Uganda and Nigeria was determined by mitochondrial DNA based phylogeny and restriction fragment length polymorphism. Cassava in these countries was infected with five whitefly populations, and each one was infected with different endosymbiotic bacteria. Incidences of Arsenophonus, Rickettsia, Wolbachia and Cardinium varied amongst the populations. Wolbachia was the most predominant symbiont with infection levels varying from 21 to 97\%. Infection levels of Arsenophonus varied from 17 to $64 \%$ and that of Rickettsia was 0 to 53\%. Hamiltonella and Fritschea were absent in all the samples. Multiple locus sequence typing identified four different strains of Wolbachia infecting cassava whiteflies. A common strain of Wolbachia infected the whitefly population Sub-Saharan Africa 1-subgroup 1 (SSA1-SG1) and SSA1-SG2, while others were infected with different strains. Phylogeny based on 165 rDNA of Rickettsia and 235 rDNA of Arsenophonus also identified distinct strains.

Conclusions: Genetically diverse bacteria infect cassava whiteflies in Africa with varied prevalence across different host populations, which may affect their whitefly biology. Further studies are required to investigate the role of endosymbionts to better understand the whitefly population dynamics.

Keywords: Cassava, Whitefly, mtCOI, Wolbachia, Rickettsia, Arsenophonus

\section{Background}

The whitefly, Bemisia tabaci (Hemiptera: Aleyrodidae) has gained importance as one of the most important agricultural pests owing to its wide geographic spread, large host range of over 500 hosts, and most significantly as a vector of over 100 different plant viruses in the tropical and subtropical regions of the world [1,2]. B. tabaci is a

\footnotetext{
* Correspondence: m.n.maruthi@greenwich.ac.uk

Natural Resources Institute, University of Greenwich, Chatham ME4 4 TB, Kent, UK
}

\section{Biomed Central}

cryptic species complex comprising at least 24 morphologically indistinguishable species [3] with a proposed origin in sub-Saharan Africa (SSA) and with high variability in mitochondrial cytochrome oxidase I (mtCOI) nucleotide sequences amongst major geographical clades $[2,4]$. Cassava, a key food security crop throughout SSA, suffers devastating yield losses due to $B$. tabaci-borne cassava mosaic begomoviruses (CMBs) and cassava brown streak viruses (CBSVs). These cause cassava mosaic disease (CMD) and cassava brown streak disease (CBSD), respectively $[5,6]$. Five genetically distinct groups 
of B. tabaci, named Sub-Saharan Africa 1 to 5 (SSA 1-5) colonise cassava in SSA. These have been generally referred to as cassava whiteflies in this and other studies. SSA1 occurs throughout the SSA, SSA2 in East and West Africa, SSA3 in Cameroon and Togo, SSA4 only in Cameroon and SSA5 in South Africa [6]. Based on mtCOI sequence divergences, SSA1 was further divided into four subgroups; SSA1- subgroup 1 (SSA1-SG1), SSA1-SG2, SSA1-SG3 and SSA1-SG4 [6].

Superabundant B. tabaci populations, commonly numbering more than 1000 adults per top five leaves, of cassava plants, have been associated with the rapid spread of CMD pandemic in East and Central Africa since the late 1990s. SSA2, the then super abundant population which was also described as the 'invader or UG2', was associated with the spread of the CMD pandemic $[7,8]$. In recent years, a shift in the B. tabaci population has occurred with the relative frequency of SSA1-SG1 increasing from $24.6 \%$ to $89.2 \%$, while the frequencies of SSA2 and SSA1-SG2 decreasing significantly from $63.9 \%$ to $1.4 \%$, and $11.5 \%$ to 1.4\%, respectively, between 1997 and 2010 [6]. The reasons for this natural shift in cassava population remain unknown. Similar shift in genetic diversity of populations are reported for $B$. tabaci species, mainly with respect to the population replacement by the invasive Middle East-Asia Minor 1 (MEAM1, previously B-biotype) and Mediterranean (MED, previously Q-biotype) populations [9-11].

In addition to the primary endosymbiont Portiera aleyrodidarum, the species $B$. tabaci has been reported to harbour six vertically transmitted secondary endosymbionts, Arsenophonus, Wolbachia, Hamiltonella, Cardinium, Fritschea and Rickettsia [12-14]. Recently, a new bacterium named Candidatus hemipteriphilus asiaticus was also found to infect B. tabaci from China [15]. Several of these endosymbionts can affect the biology and behaviour of B. tabaci. Wolbachia and Cardinium in particular are known to induce cytoplasmic incompatibility $(\mathrm{CI})$, a process in which the host reproduction is manipulated to allow rapid spread of bacteria through insect populations [16]. Whether such phenotypes are induced by these bacteria in B. tabaci remains unknown. Rickettsia, when infecting MEAM1, provided fitness benefits by increased fecundity and survival [17], increased heat stress tolerance [18], defence against pathogens [19] but occasionally also increased the susceptibility to insecticides [20]. Fritschea has reported negative impact with reduced fecundity and narrowing the host range of infected New World species of whiteflies [21]. Endosymbionts can also alter the vector ability of $B$. tabaci. Hamiltonella in MEAM1 and Arsenophonus in Asia II populations facilitated virus transmission by releasing a bacterial chaperonin GroEL that binds and protects virus particles during their transit through the insect body [22,23]. Hamiltonella in the MED and Rickettsia in MEAM1 populations are also reported to increase acquisition, retention and transmission of Tomato yellow leaf curl virus [24,25]. The study of intracellular bacterial communities in these whiteflies and their impact on the host was essential for understanding the dynamics of insect populations and their vector abilities. In this study, we identified the endosymbionts infecting cassava whiteflies, determined their infection frequencies in different populations and characterised the diverse bacterial species by sequencing. We have also developed a cost effective and reliable restriction fragment length polymorphism (RFLP) diagnostic method for the molecular typing of the cassava whitefly populations.

\section{Results}

RFLP for molecular typing of cassava whiteflies

The mtCOI locus has been the most commonly used marker for genotyping whiteflies but the cost and time involved in gene sequencing and analysis are a limiting factor for routine diagnosis and processing large number of samples in epidemiological studies. We therefore developed a quick and cost-effective RFLP technique as an alternative to type SSA cassava whiteflies used in this study that efficiently identified the different populations. The RFLP was carried out in two steps. In the first step, digesting mtCOI products with $B g l$ II cleaved SSA2 into two fragments of size 615 and 252 bp but did not cleave mtCOI loci from other populations (Figure 1a). In the second step, digesting mtCOI products from SSA1 and SSA3 with Apo I and Dde I produced 2 to 5 fragments of distinctive sizes (Figure 1b). SSA1-SG1 and SSA3 were distinguished by the presence of fragments 122 and 213 bp, respectively. SSA1-SG2, SSA1-SG3 and SSA1SG5 were identified by the presence of bigger fragments of 493, 402 and $344 \mathrm{bp}$, respectively (Figure 1b). These patterns were obtained consistently on 20 samples digested for each population. Fragments below $100 \mathrm{bp}$ size were not visualised reliably on agarose gels, which were therefore discounted from the analysis.

\section{Cassava whitefly diversity and detection}

The mtCOI locus of cassava whiteflies indicated the predominance of SSA1 populations in the countries sampled, the only other group present was SSA3 in Nigeria. All B. tabaci samples analysed from Tanzania (35 out of 35) belonged to SSA1-SG3 type. In Malawi, about $89.1 \%$ (41/46) whiteflies were SSA1-SG3 and the remaining 10.8\% (5/46) were SSA1-SG2. In Uganda, 69.4\% (68/98) were SSA1-SG1 and 30.6\% (30/98) were SSA1-SG2 (Figure 2). The Nigerian (Ibadan) populations belonged to the SSA1 group in the phylogenetic trees but did not cluster with any of the known four sub-groups. They clustered separately with sequences from Ghana from the database; they are therefore referred to as SSA1- 


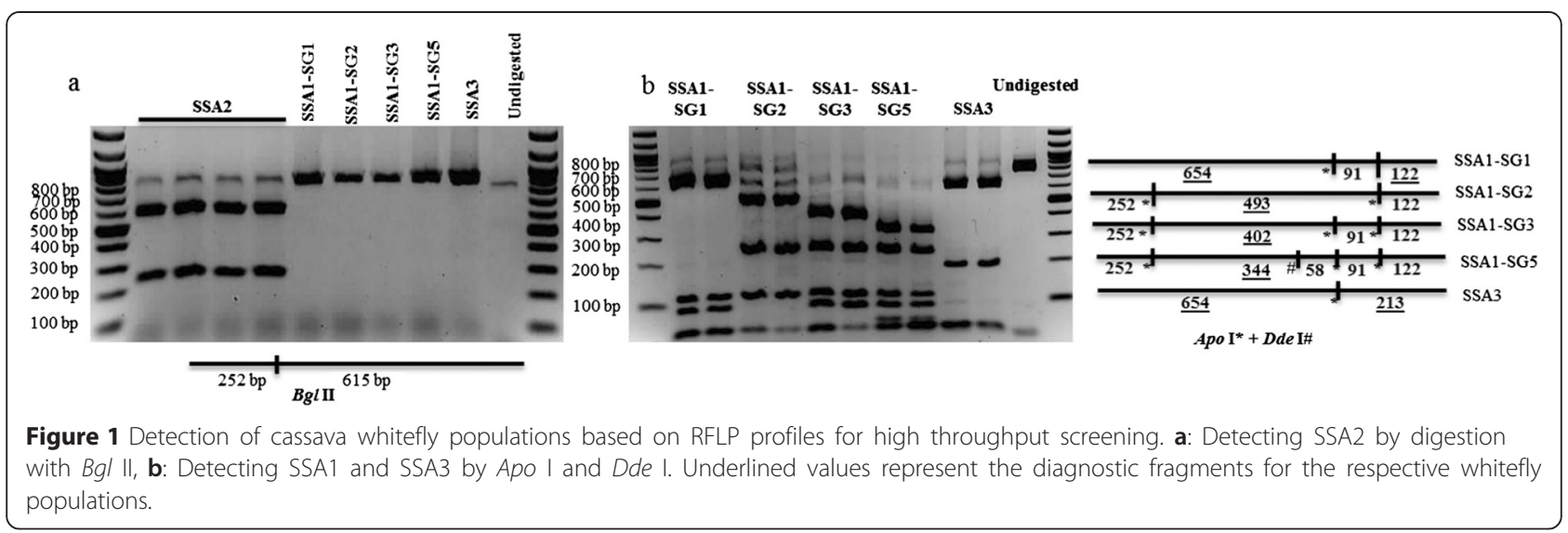

SG5 (Figure 3). In Nigeria, 60.3\% (41/68) were SSA1SG5, 35.3\% (24/68) SSA3 and 4.4\% (3/68) were SSA1SG1 type (Figure 2). SSA2 and SSA1-SG4 were not found in our study.

\section{Prevalence of bacterial endosymbionts}

The primary endosymbiont Portiera was detected in all the samples as expected. The secondary symbionts were found in $77.3 \%$ (191 whiteflies infected out of 247 tested) of the insects and their prevalence varied significantly across the different whitefly populations (Figure 4). The overall infection frequencies of Wolbachia, Arsenophonus, Rickettsia and Cardinium in the cassava whiteflies were 49.4\% (122/247), 40.5\% (100/247), 22.3\% (55/247) and
0.8\% (2/247), respectively. Hamiltonella and Fritschea were not detected in any of the whiteflies tested.

Highest and lowest rates of infection by Arsenophonus were seen in SSA1-SG3 $(64.5 \%, 49 / 76)$ and SSA1-SG2 (17.1\%, 6/35), respectively (see Additional file 1: Table S2). Arsenophonus was present mostly as double infections, with Wolbachia in SSA1-SG1 (17\%) and SSA1SG2 (11\%), and with Rickettsia in SSA1-SG3 (28\%). Arsenophonus was present in SSA1-SG5 and SSA3 mainly as single infections (Figure 5).

Rickettsia was absent in SSA1-SG5 but most abundant in SSA1-SG3 $(53.9 \%, 41 / 76)$ followed by SSA1-SG2 $(20 \%, 7 / 35)$. Its infection levels in other populations were negligible. Cardinium was the least prevalent endosymbiont,

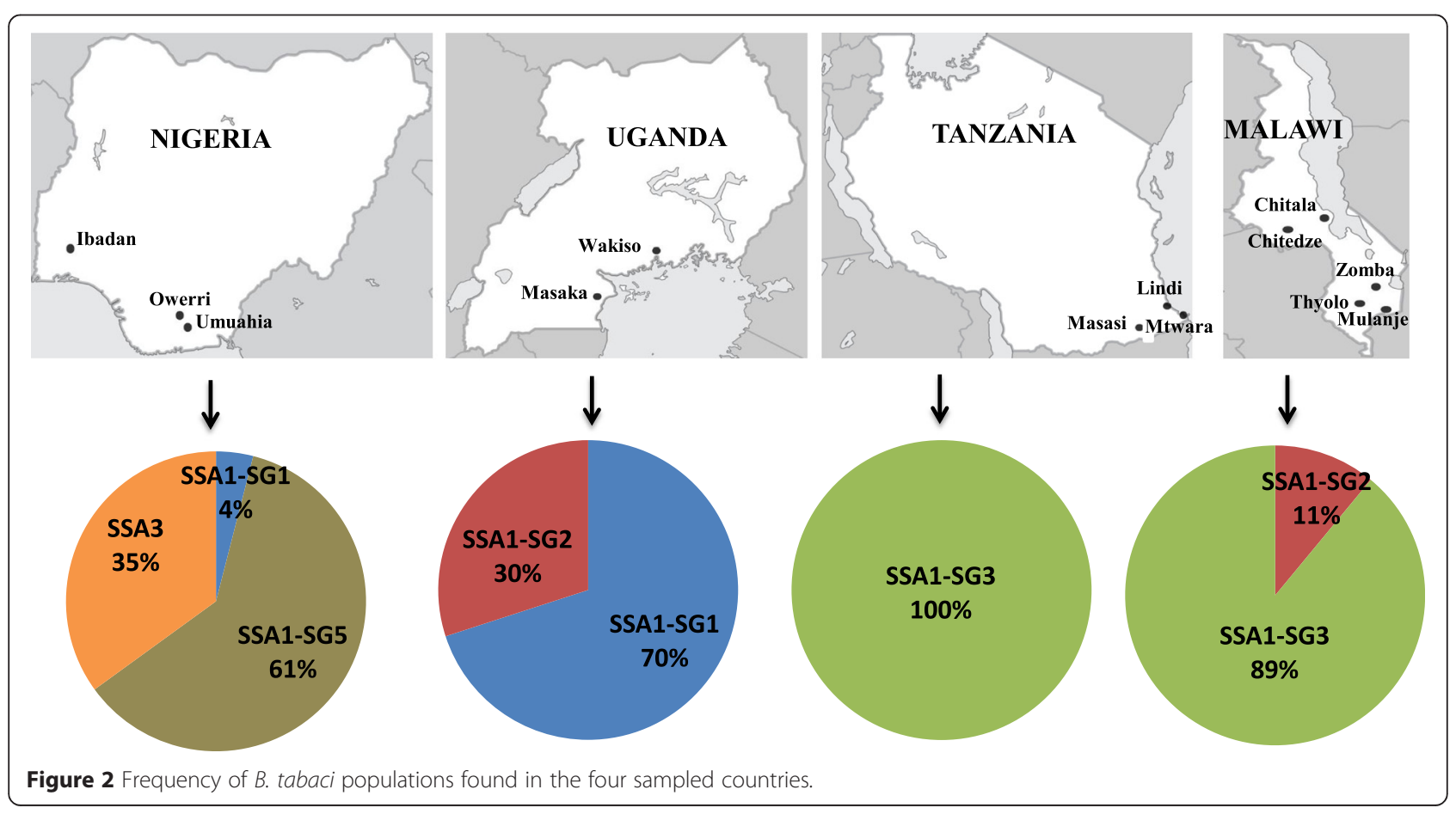




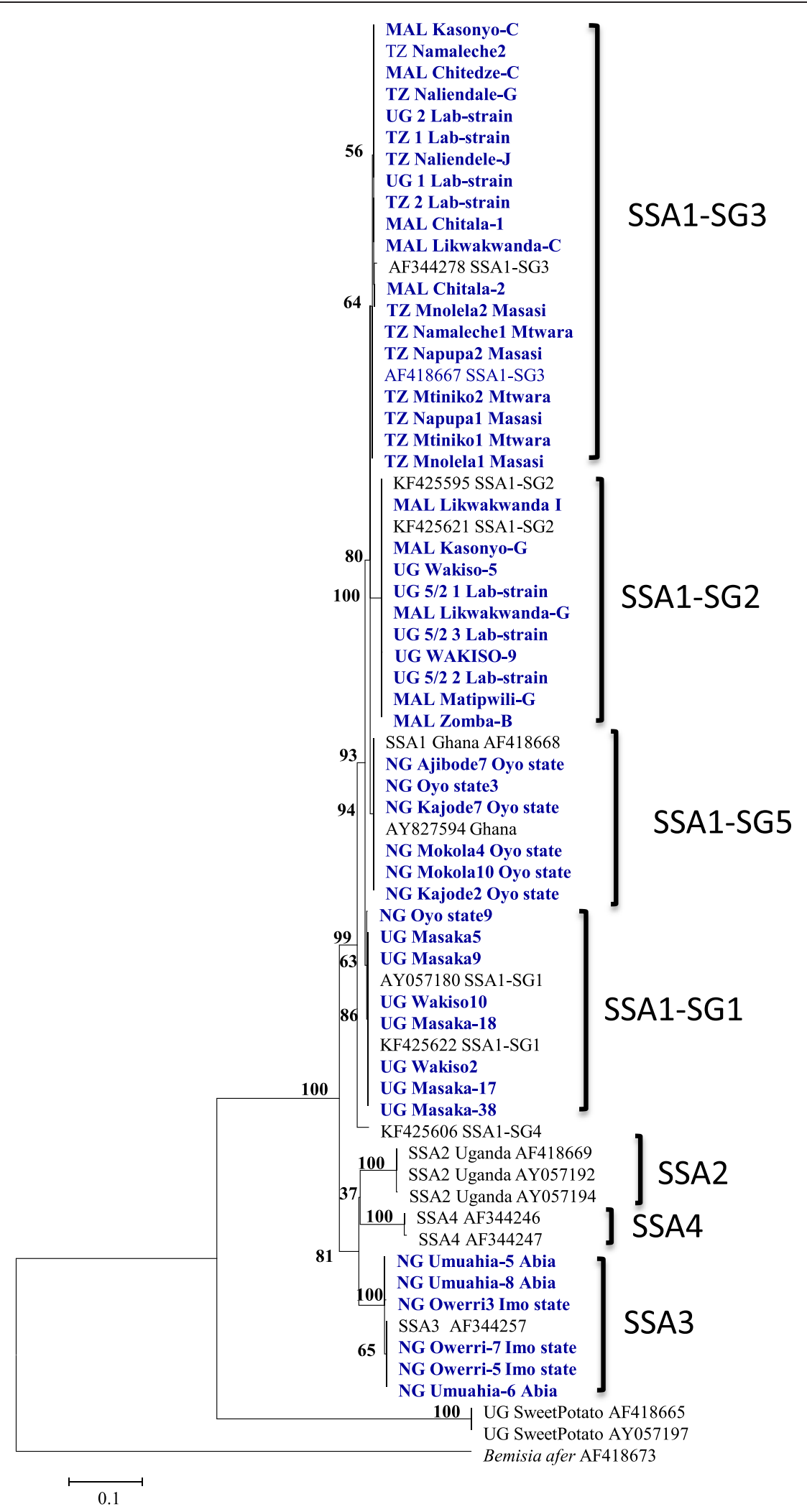

Figure 3 Phylogeny of mtCOI nucleotide sequences (697 bp) of B. tabaci infesting cassava together with reference sequences from Genbank. Genbank accession numbers for the submitted sequences are KM377899 to KM377952, and KM407138 to KM407141. 

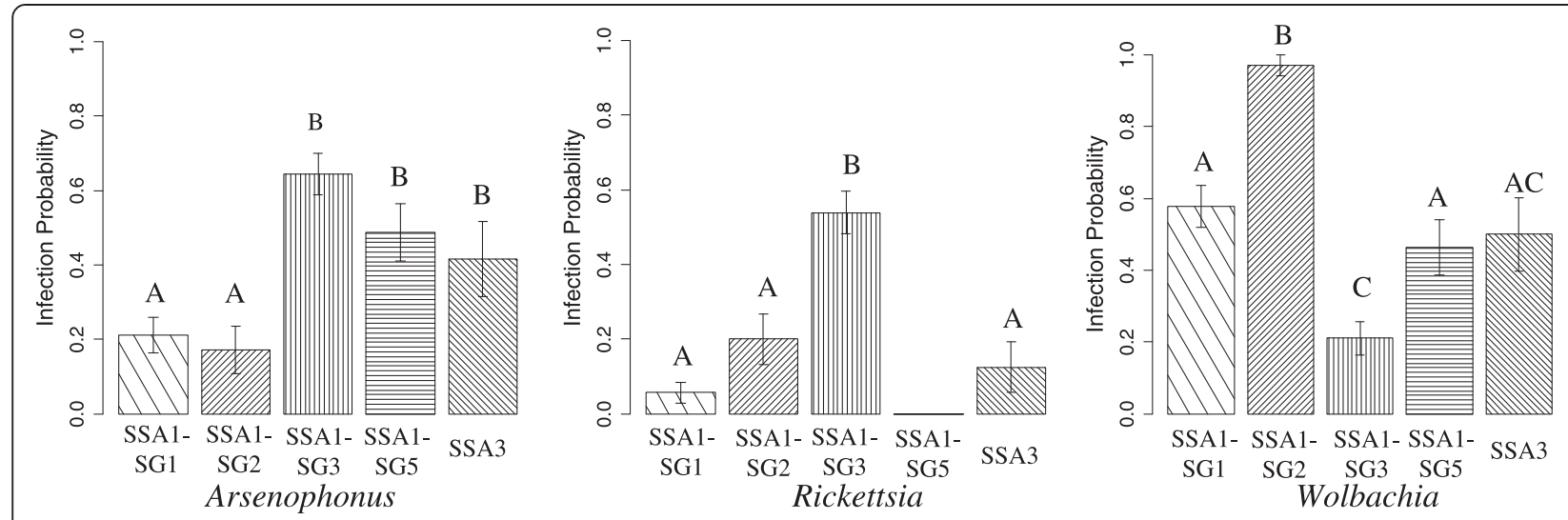

Figure 4 Mean infection probabilities of symbionts in the five cassava whitefly populations as determined by simple binomial logistic regression. Mean infection probability of a symbiont within the populations was compared by Tukey's HSD test and significant difference is indicated by different letters.

detected only in 2 out of the 76 SSA1-SG3 (2.6\%) but not in other populations.

Wolbachia was most abundant amongst the secondary bacteria and was the commonest symbiont in SSA1-SG1 and SSA1-SG2 populations, mostly as single infections (Figure 5). It was nearly fixed in SSA1-SG2 (97.1\%, 34/35), and was much higher compared to infections seen in all other populations (see Additional file 1: Table S2).

A high percentage of whiteflies were completely free of secondary symbionts in SSA1-SG1 (38.0\%) followed by SSA1-SG5 (29.2\%), SSA3 (25.0\%), SSA1-SG3 (13.1\%), and only $2.8 \%$ in SSA1-SG2 (Figure 5). Cassava whiteflies predominantly were singly infected by a symbiont $(59.1 \%, 113 / 191)$, mostly by Wolbachia $(34.0 \%, 65 / 191)$ whereas only $36.6 \%(70 / 191)$ and $4.1 \%(8 / 191)$ had double and triple infections, respectively. Co-infections were commonest in SSA1-SG3 (54.5\%, 36/66) (Figure 5).

\section{Genetic diversity of endosymbionts}

All five MLST fragments were amplified from Wolbachia infections from SSA1-SG2 and SSA1-SG3 from East African B. tabaci populations. However, only $\operatorname{coxA}$ was
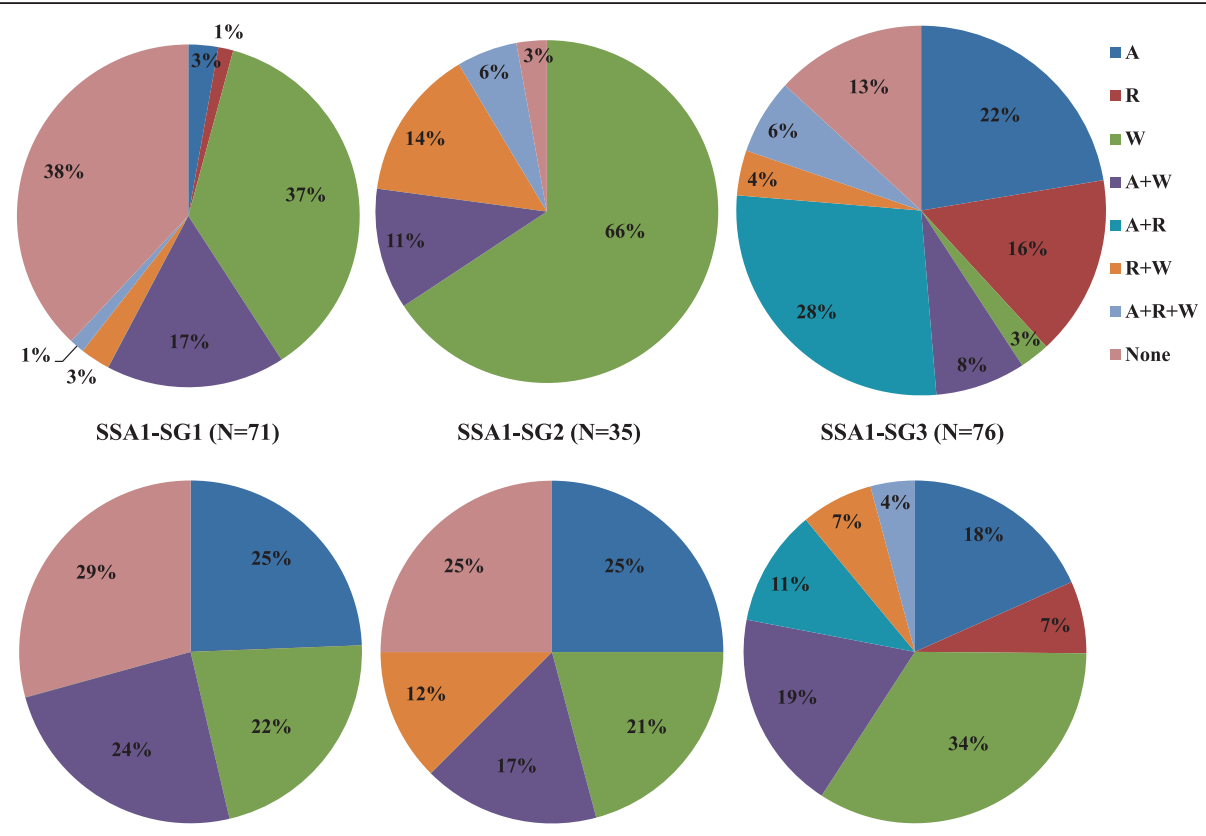

SSA1-SG2 (N=35)

SSA1-SG3 (N=76)
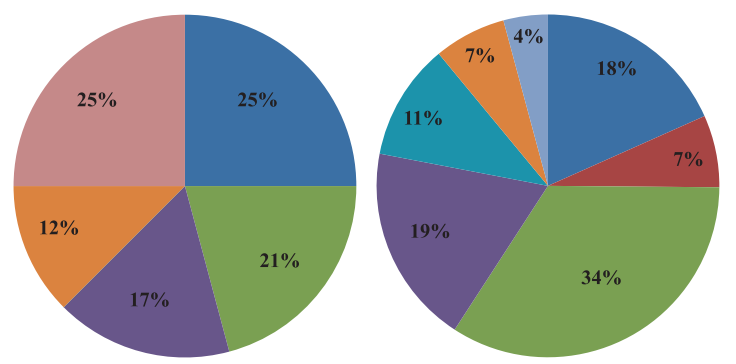

SSA3 ( $=24)$

Cassava whiteflies $(\mathrm{N}=191)$

Figure 5 Pattern of infections of symbionts in different whitefly populations. Alphabets represent infection by each symbiont, $\mathrm{A}=$ Arsenophonus, $\mathrm{R}=$ Rickettsia, $\mathrm{W}=$ Wolbachia, $\mathrm{C}=$ Cardinium, None $=$ free of secondary endosymbionts). 
amplified from SSA1-SG5 and none from SSA3 from Nigeria despite exhaustive efforts. For SSA1-SG1, only $\operatorname{cox} A$, fts $Z$, gat $B$ and $h c p A$ were amplified except for one sample for which all five MLST markers were amplified.

Four unique Wolbachia sequence types were identified in this study, which were all submitted to the Wolbachia pubMLST database (Table 1). SSA1-SG1 and SSA1-SG2 were infected with identical Wolbachia based on five MLST alleles. These were unique to African cassava whiteflies as they shared no allele from other reported Wolbachia from B. tabaci but shared four common alleles with Eretmocerus sp. (parasitoid of whitefly), butterflies and Spodoptera exempta from wide geographical distances in the USA, Japan, India and Tanzania (Table 1). In contrast, SSA1-SG3 was infected with two different Wolbachia, but they shared three alleles $(\operatorname{cox} A=88$, $h c p A=106, f b p A=9$ ) with $B$. tabaci from China and USA. Phylogeny of the concatenated MLST sequences of Wolbachia from whiteflies clustered into three subclades, W1, W2 and W3 (Figure 6). W1 sequences were from SSA1-SG1 and SSA1-SG2, and these were closely related ( $\geq 99.9 \%$ identical, Table 2 ) to Culex and butterfly species (Hypolimnus, Cepora and Telicada). W2 isolates contained SSA1-SG3, and was closer to Wolbachia from B. tabaci from other geographical regions and host plants. W3 consisted of isolates from B. tabaci from Asia and Bemisia afer from Nigeria. Similar results were obtained when the phylogenetic analysis of the wsp gene was sequenced for Wolbachia as the SSA1-SG1 and SSA1-SG2 were clustered together and separately from SSA1-SG3 (Figure 7). Comparison of Wolbachia strains showed that W1 isolates differed by a minimum of $4.5 \%$ nucleotides from W2 and W3 isolates, and W2 and W3 isolates differed by a minimum of $1 \%$ for MLST sequences (Table 2).

The 23S rDNA sequences of Arsenophonus from cassava whiteflies clustered into three sub clades A1, A2, A3 with bootstrap scores of $>70 \%$ (Figure 8). A3 isolates differed by $5.8 \%$ from $\mathrm{A} 1$, and $9.4 \%$ from $\mathrm{A} 2$ isolates (Table 3). These were incongruent with the evolution of the whitefly host based on mtCOI phylogeny. The samples belonging to clade A3 had additional $160 \mathrm{bp}$ sequences and closely related (99.5\% identity, Table 3 ) to sequences from Arsenophonus nasoniae, a male killing endosymbiont in the parasitic wasp, Nasonia vitripennis. One SSA1-SG2 and SSA1-SG3 sample was each infected by both A2 and A3 strains of Arsenophonus.

The Rickettsia 16S rDNA sequences grouped into two clusters, R1 and R2 (Figure 9) with more than 8.5\% nucleotide distances between them (Table 4). R1 strains were detected only in SSA1-SG3 and SSA1-SG2 populations and were identical to the Rickettsia from invasive MEAM1 and MED species which were closer to strains from Rickettsia sp. nr Bellii. R2 strains were identical to

Table 1 Comparison of MLST profile of Wolbachia from cassava B. tabaci with those from the pubMLST database, specimens in bold were generated in this study

\begin{tabular}{|c|c|c|c|c|c|c|c|c|}
\hline Host & Super group & Country & $\operatorname{cox} A$ & $f b p A$ & $f t s Z$ & gat $B$ & hсpA & Sequence type \\
\hline B. tabaci (SSA1-SG1) & B & Uganda & 14 & 4 & 73 & 4 & 3 & $423^{*}$ \\
\hline B. tabaci (SSA1-SG2) & B & Malawi, Uganda & 14 & 4 & 73 & 4 & 3 & $423^{*}$ \\
\hline B. tabaci (SSA1-SG3) & B & Tanzania, Malawi & 88 & 9 & 105 & 9 & 106 & $424^{*}$ \\
\hline B. tabaci (SSA1-SG3) & B & Tanzania & 88 & $404^{*}$ & 105 & 9 & 106 & $425^{*}$ \\
\hline B. tabaci (SSA1-SG5) & B & Nigeria & 88 & - - & 一一 & -—- & - - & \\
\hline B. afer & B & Nigeria & 88 & 89 & $198^{*}$ & 105 & 106 & $427^{*}$ \\
\hline B. tabaci (MED) & B & USA & 88 & 165 & 7 & 105 & 106 & 166 \\
\hline B. tabaci (China I) & B & China & 88 & 9 & 170 & 207 & 13 & 377 \\
\hline B. tabaci (Asia II 1) & B & China & 88 & 390 & 170 & 207 & 234 & 391 \\
\hline B. tabaci (China 1) & B & China & 88 & 9 & 170 & 105 & 13 & 379 \\
\hline B. tabaci (Asia II 7) & B & China & 88 & 387 & 7 & 105 & 106 & 378 \\
\hline B. tabaci (Asia 1) & B & China & 88 & 387 & 182 & 207 & 106 & 395 \\
\hline B. tabaci (Australia) & B & Australia & 88 & 9 & 170 & 207 & 221 & 380 \\
\hline B. tabaci (Asia \|I 9) & B & China & 88 & 386 & 170 & 207 & 13 & 384 \\
\hline Eretmocerus sp. nr. emiratus & B & USA & 14 & 4 & 73 & 105 & 3 & 161 \\
\hline Hypolimnus bolina & B & Japan & 14 & 4 & 73 & 4 & 40 & 125 \\
\hline Telicada nyseus & B & India & 14 & 4 & 73 & 4 & 40 & 125 \\
\hline Spodoptera exempta & B & Tanzania & 14 & 4 & 73 & 4 & 40 & 125 \\
\hline Cepora nerissa & B & India & 14 & 4 & 36 & 4 & 3 & 145 \\
\hline
\end{tabular}

'*'New additions of Wolbachia sequence types to the database by this study, and '-—' failure to amplify genes in PCR amplifications. 


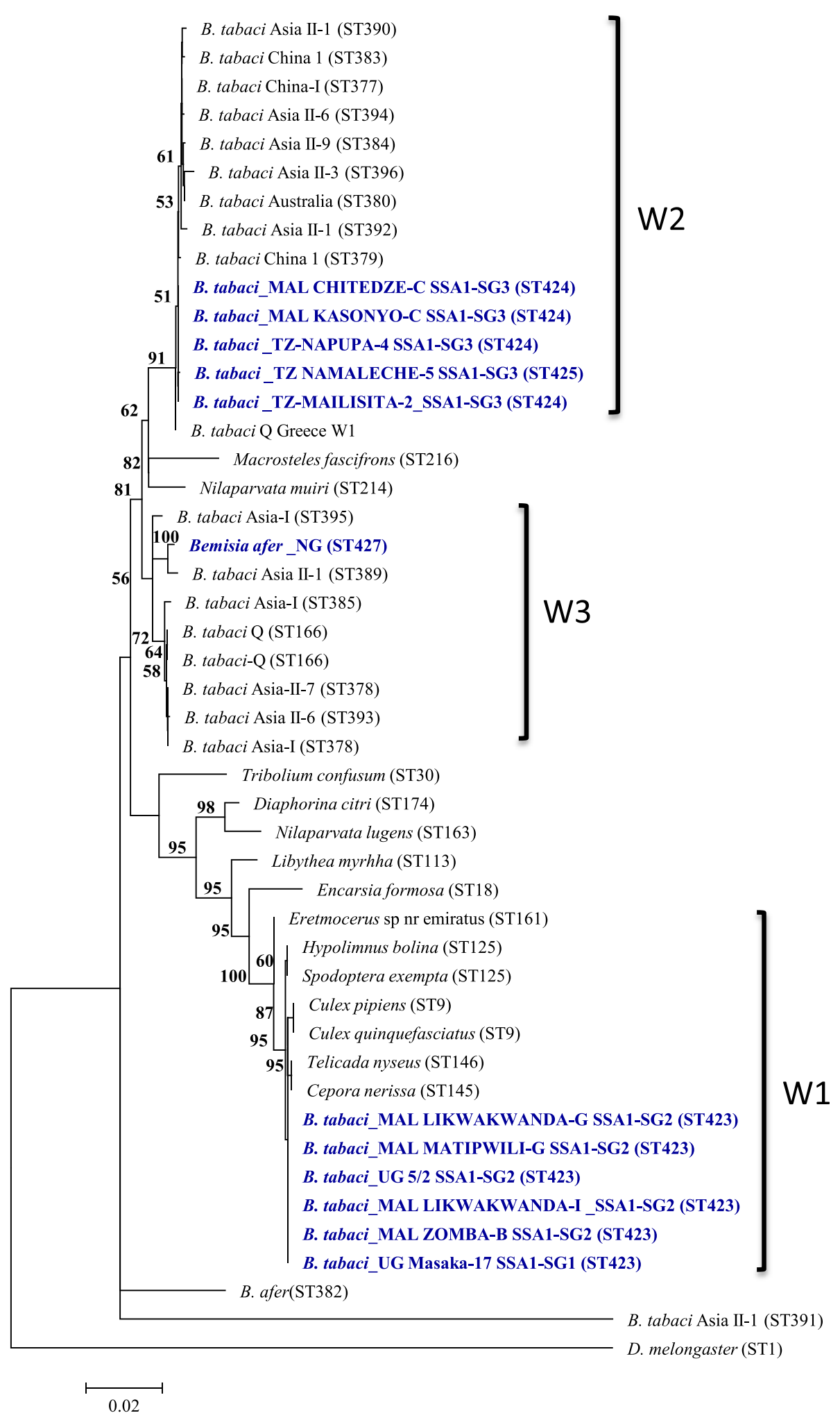

Figure 6 Phylogeny of concatenated MLST (2079 bp) nucleotide sequences of Wolbachia infecting whiteflies and other insect species. Strain names in the parentheses indicate the various Wolbachia sequence types. 
Table 2 Percentage nucleotide identities of selected Wolbachia strains based on concatenated MLST sequences (p-distances were calculated using MEGA 5.0) UG-5/2_SSA1-SG2 (423)

\begin{tabular}{|c|c|c|c|c|c|c|c|c|c|c|c|c|c|c|c|c|c|c|c|}
\hline MAL_SSA1-SG2 (423) & 100 & & & & & & & & & & & & & & & & & & \\
\hline UG_SSA1-SG1 (423) & 100 & 100 & & & & & & & & & & & & & & & & & \\
\hline H bolina (125) & 99.95 & 99.95 & 99.95 & & & & & & & & & & & & & & & & \\
\hline C pipiens_(9) & 99.90 & 99.90 & 99.90 & 99.86 & & & & & & & & & & & & & & & \\
\hline Eretmocerus (161) & 99.71 & 99.71 & 99.71 & 99.66 & 99.61 & & & & & & & & & & & & & & \\
\hline MAL_SSA1-SG3 (424) & 95.56 & 95.56 & 95.56 & 95.61 & 95.47 & 95.85 & & & & & & & & & & & & & \\
\hline TZ_SSA1-SG3 (424) & 95.56 & 95.56 & 95.56 & 95.61 & 95.47 & 95.85 & 100 & & & & & & & & & & & & \\
\hline TZ_SSA1-SG3 (425) & 95.51 & 95.51 & 95.51 & 95.56 & 95.42 & 95.80 & 99.95 & 99.95 & & & & & & & & & & & \\
\hline China-I (377) & 95.47 & 95.47 & 95.47 & 95.51 & 95.37 & 95.75 & 99.90 & 99.90 & 99.86 & & & & & & & & & & \\
\hline Asia_II-3 (396) & 95.27 & 95.27 & 95.27 & 95.32 & 95.18 & 95.56 & 99.61 & 99.61 & 99.57 & 99.71 & & & & & & & & & \\
\hline Asia_II-9 (384) & 95.42 & 95.42 & 95.42 & 95.47 & 95.32 & 95.71 & 99.86 & 99.86 & 99.81 & 99.95 & 99.76 & & & & & & & & \\
\hline Australia (380) & 95.47 & 95.47 & 95.47 & 95.51 & 95.37 & 95.75 & 99.86 & 99.86 & 99.81 & 99.95 & 99.76 & 99.90 & & & & & & & \\
\hline B afer_Nigeria (427) & 96.53 & 96.53 & 96.53 & 96.58 & 96.43 & 96.82 & 98.22 & 98.22 & 98.17 & 98.12 & 97.88 & 98.07 & 98.07 & & & & & & \\
\hline MED (166) & 96.19 & 96.19 & 96.19 & 96.24 & 96.09 & 96.48 & 98.99 & 98.99 & 98.94 & 98.89 & 98.65 & 98.84 & 98.84 & 99.23 & & & & & \\
\hline Asia_II-1 (389) & 96.24 & 96.24 & 96.24 & 96.29 & 96.14 & 96.53 & 98.22 & 98.22 & 98.17 & 98.31 & 98.02 & 98.26 & 98.26 & 99.61 & 99.04 & & & & \\
\hline Asia_II-6 (393) & 96.09 & 96.09 & 96.09 & 96.14 & 96.00 & 96.38 & 98.99 & 98.99 & 98.94 & 98.89 & 98.65 & 98.84 & 98.84 & 99.13 & 99.90 & 98.94 & & & \\
\hline Asia-II-7 (378) & 96.14 & 96.14 & 96.14 & 96.19 & 96.04 & 96.43 & 99.04 & 99.04 & 98.99 & 98.94 & 98.70 & 98.89 & 98.89 & 99.18 & 99.95 & 98.99 & 99.95 & & \\
\hline$B$ afer (382) & 95.18 & 95.18 & 95.18 & 95.22 & 95.18 & 95.47 & 96.62 & 96.62 & 96.58 & 96.53 & 96.29 & 96.48 & 96.48 & 96.33 & 95.90 & 96.04 & 95.80 & 95.85 & \\
\hline D melongaster (1) & 88.08 & 88.08 & 88.08 & 88.13 & 87.99 & 88.23 & 89.10 & 89.10 & 89.05 & 89.10 & 88.95 & 89.05 & 89.05 & 88.47 & 88.86 & 88.47 & 88.86 & 88.90 & 88.95 \\
\hline
\end{tabular}




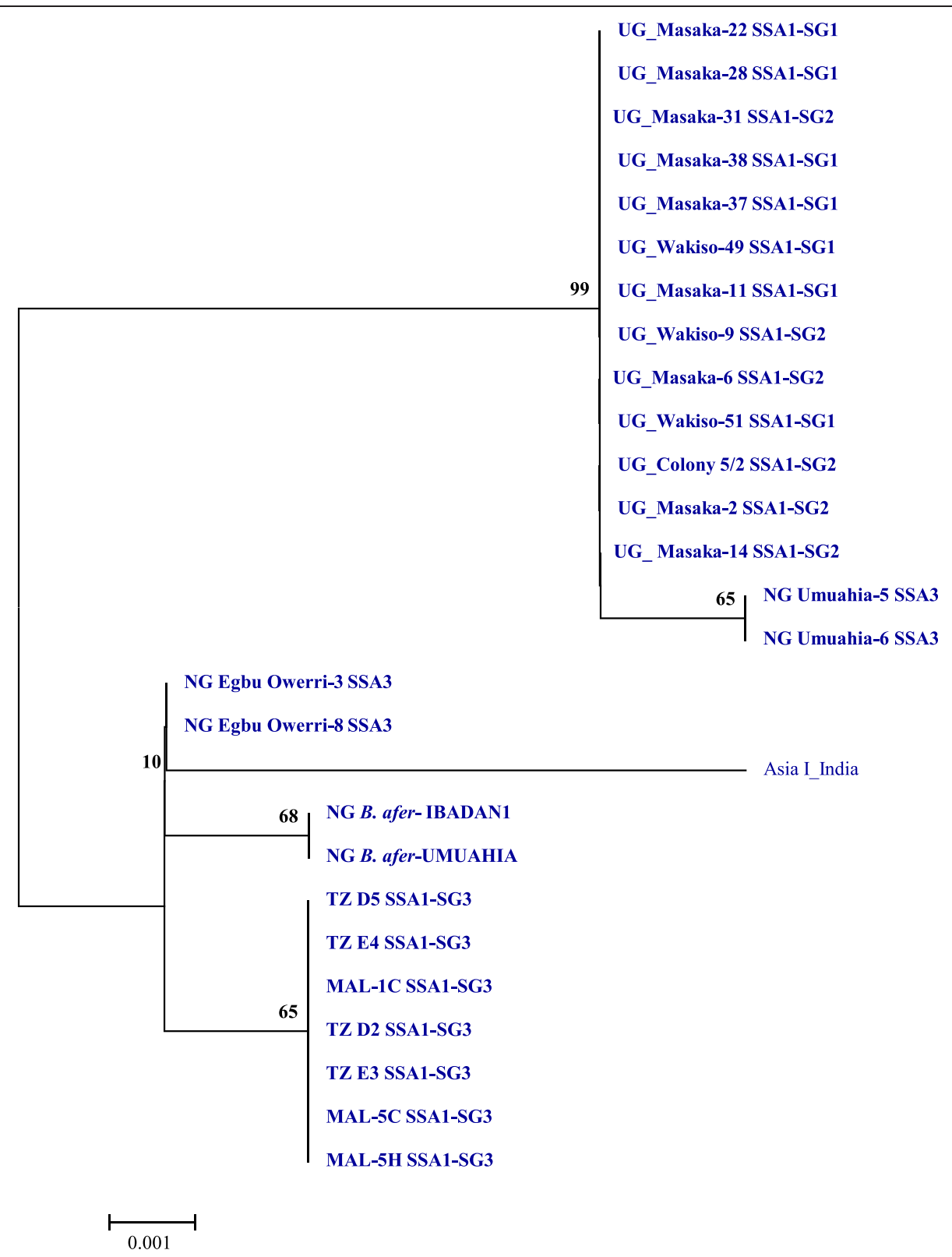

Figure 7 Phylogeny of Wolbachia wsp (596 bp) nucleotide sequences infecting cassava whiteflies in sub-Saharan Africa. Genbank accession numbers for submitted sequences are KP208705 to KP208733.

the other strains from native whiteflies from India and China. Cardinium was detected only in SSA1-SG3 and the sequences were identical to the strains infecting Indian whiteflies (Figure 10).

\section{Discussion}

The main aim of this study was to determine the prevalence and genetic diversity of secondary endosymbionts infecting cassava whiteflies in SSA. Whiteflies harbour multiple bacterial symbionts that play essential roles on insect biology, evolution and virus transmission. Understanding cassava whitefly diversity and the bacterial communities co-existing, within the cassava ecosystem is essential to understand the near extinction of some cassava populations in recent years, or the development of superabundant populations and the resultant epidemics of CMD and CBSD in Eastern and Central African countries in recent years [8,26,27].

At first, the genetic diversity of cassava whiteflies from Uganda, Tanzania, Malawi and Nigeria was studied by mtCOI sequence. This was done to establish the correlation between the prevalence of symbionts in different whitefly populations. Cassava in these countries was colonised by five genetically different whitefly populations. 


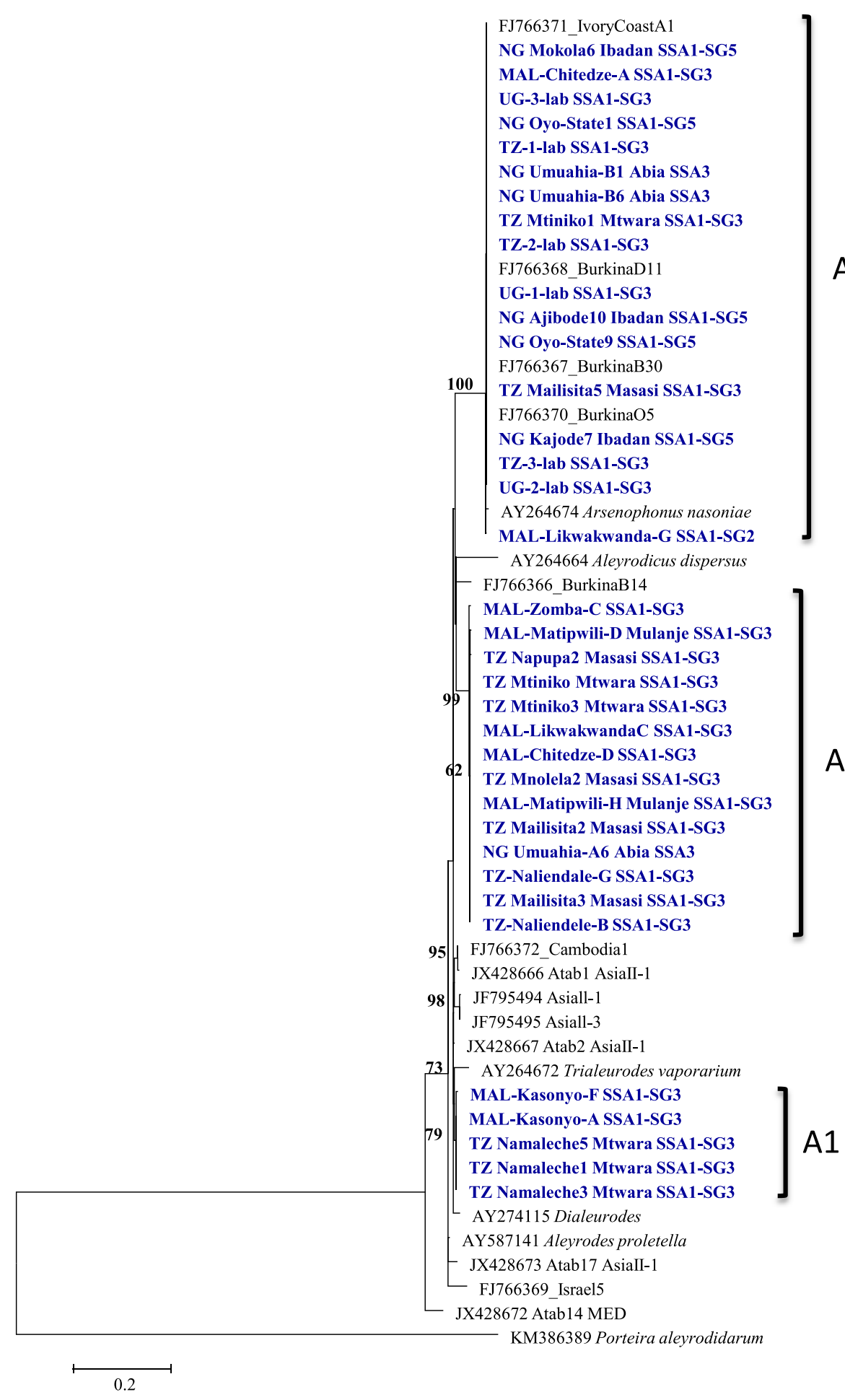

Figure 8 Phylogeny of Arsenophonus infecting whitefly species based on 235 rDNA (401 bp) nucleotide sequences. Genbank accession numbers for the submitted sequences are KM377863 to KM377898.

SSA1 and its various sub-groups was predominant in the countries sampled, the only other group present was SSA3 in Nigeria, while SSA2 was not detected. Only SSA1-SG3 was found in coastal Tanzania, while Malawi had high proportions of SSA1-SG3 (89.1\%) than Uganda SSA1-SG1 (69.4\%) (Figure 2). Based on mtCOI phylogeny, a new 
Table 3 Percentage nucleotide identities of 23S rDNA sequences of Arsenophonus strains (p-distances were calculated using MEGA 5.0)

\begin{tabular}{|c|c|c|c|c|c|c|c|c|c|c|c|c|c|c|c|}
\hline TZ_Namaleche1_SSA1-SG3 & & & & & & & & & & & & & & & \\
\hline TZ_Namaleche3_SSA1-SG3 & 100 & & & & & & & & & & & & & & \\
\hline MAL-Kasonyo-F_SSA1-SG3 & 99.8 & 99.8 & & & & & & & & & & & & & \\
\hline TZ-Naliendale-B_SSA1-SG3 & 95.4 & 95.4 & 95.2 & & & & & & & & & & & & \\
\hline NG_Umuahia-A6_SSA3 & 95.4 & 95.4 & 95.2 & 100 & & & & & & & & & & & \\
\hline MAL-Zomba-C_SSA1-SG3 & 95.2 & 95.2 & 94.9 & 99.8 & 99.8 & & & & & & & & & & \\
\hline TZ-1-lab_SSA1-SG3 & 94.2 & 94.2 & 94.0 & 90.6 & 90.6 & 90.8 & & & & & & & & & \\
\hline MAL-Chitedze-A_SSA1-SG3 & 94.2 & 94.2 & 94.0 & 90.6 & 90.6 & 90.8 & 100 & & & & & & & & \\
\hline NG_Oyo-State1_SSA1-SG5 & 94.2 & 94.2 & 94.0 & 90.6 & 90.6 & 90.8 & 100 & 100 & & & & & & & \\
\hline AY264674_A_nasoniae & 94.2 & 94.2 & 94.0 & 90.6 & 90.6 & 90.8 & 99.5 & 99.5 & 99.5 & & & & & & \\
\hline FJ766366_ASL_Burkina_Faso & 95.7 & 95.7 & 95.4 & 96.4 & 96.4 & 96.1 & 91.1 & 91.1 & 91.1 & 91.1 & & & & & \\
\hline FJ766370_MED_Burkina_Faso & 94.2 & 94.2 & 94.0 & 90.6 & 90.6 & 90.8 & 100 & 100 & 100 & 99.5 & 91.1 & & & & \\
\hline JX428666_Asiall_1 & 98.1 & 98.1 & 97.8 & 95.9 & 95.9 & 95.7 & 92.8 & 92.8 & 92.8 & 92.8 & 95.7 & 92.8 & & & \\
\hline JF795495_Asiall_3 & 98.3 & 98.3 & 98.1 & 95.2 & 95.2 & 94.9 & 93.2 & 93.2 & 93.2 & 93.2 & 95.4 & 93.2 & 97.8 & & \\
\hline FJ766369_MED_Israel & 94.7 & 94.7 & 94.4 & 92.3 & 92.3 & 92.0 & 89.6 & 89.6 & 89.6 & 89.6 & 92.3 & 89.6 & 93.7 & 94.0 & \\
\hline JX428672_MED_China & 91.5 & 91.5 & 91.3 & 91.3 & 91.3 & 91.1 & 87.0 & 87.0 & 87.0 & 87.0 & 90.6 & 87.0 & 91.5 & 91.8 & 89.4 \\
\hline
\end{tabular}

population was found in Nigeria, which we referred to as SSA1-SG5 (Figure 3). SSA1-SG5 was predominant (60.3\%) in Nigeria, followed by SSA3 (35.3\%) and a very few individuals of SSA1-SG1 (4.4\%). Overall, these results are concurrent with the previous studies that have also shown high levels of genetic diversity amongst the cassava whitefly populations in SSA [6,27-29].

As seen above and in previous studies, mtCOI is shown to be a reliable marker for separating whitefly species and sub-populations. However, using this as a marker requires sequencing and thus incurs high costs and time. In addition, the threat of the two cassava virus disease pandemics spread by the superabundant $B$. tabaci populations requires simpler monitoring system for effective disease management. We therefore developed a robust RFLP method for typing cassava whiteflies relatively quickly. Using the two-step method and three restriction enzymes described in this study, we were able to reliably assign whiteflies to phylogenetic groups and subgroups found in this study, and thus saving costs as well as time.

Typing the various bacteria infecting these whiteflies, however, proved far more challenging as some of the methods and primers described in the literature did not work initially on cassava whitefly endosymbionts. This was probably because of the high genetic diversity seen in both cassava whiteflies and the various bacteria that infected them. New primers were therefore developed where necessary and the DNA extraction methods and PCR conditions were optimised. Diagnosis of various bacteria confidently was a pre-requisite to understand the genetic diversity of bacteria infecting cassava whiteflies.
Using the above methods, genetically diverse bacteria were found to infect cassava whiteflies in SSA. Rickettsia, Arsenophonus, Wolbachia and Cardinium were detected in cassava whiteflies, but not Hamiltonella and Fritschea. Hamiltonella was also absent in other native whitefly populations in India and China [30,31], but was reported to be present in SSA1 cassava whiteflies from Tanzania [32]. This is contrasting to our study, and we cannot clearly explain the differences between the two studies at this time. Some of the possible explanations, however, include high site to site variation seen in endosymbiont profiles of cassava whiteflies within a country (Tajebe L., pers comm), and that our samples may have been collected coincidentally from Hamiltonella-free sites. Other reasons include the low titre of the bacteria in our samples which was beyond the limits of PCR detection, or primer mismatch in PCR reactions. We did obtain unspecific amplification of Arsenophonus from Hamiltonellaspecific primers in initial studies, which indicated primer mismatch. The Hamiltonella-specific primers, therefore, should be used with care in future studies, while the Hamiltonella quandary between Tajebe et al. [32] and this study remains to be resolved. We used MLST to characterise Wolbachia. All five MLST alleles were amplified from all our populations except only $\operatorname{cox} A$ was amplified from SSA1-SG5 and none from SSA3 after exhaustive efforts. Difficulties in amplification of MLST alleles have been reported previously, and could be due to high variability of these genes or low titres of the symbiont $[33,34]$. The surface protein $w s p$ was therefore used as an alternative marker and this marker also confirmed the high diversity of Wolbachia infecting cassava whiteflies. 


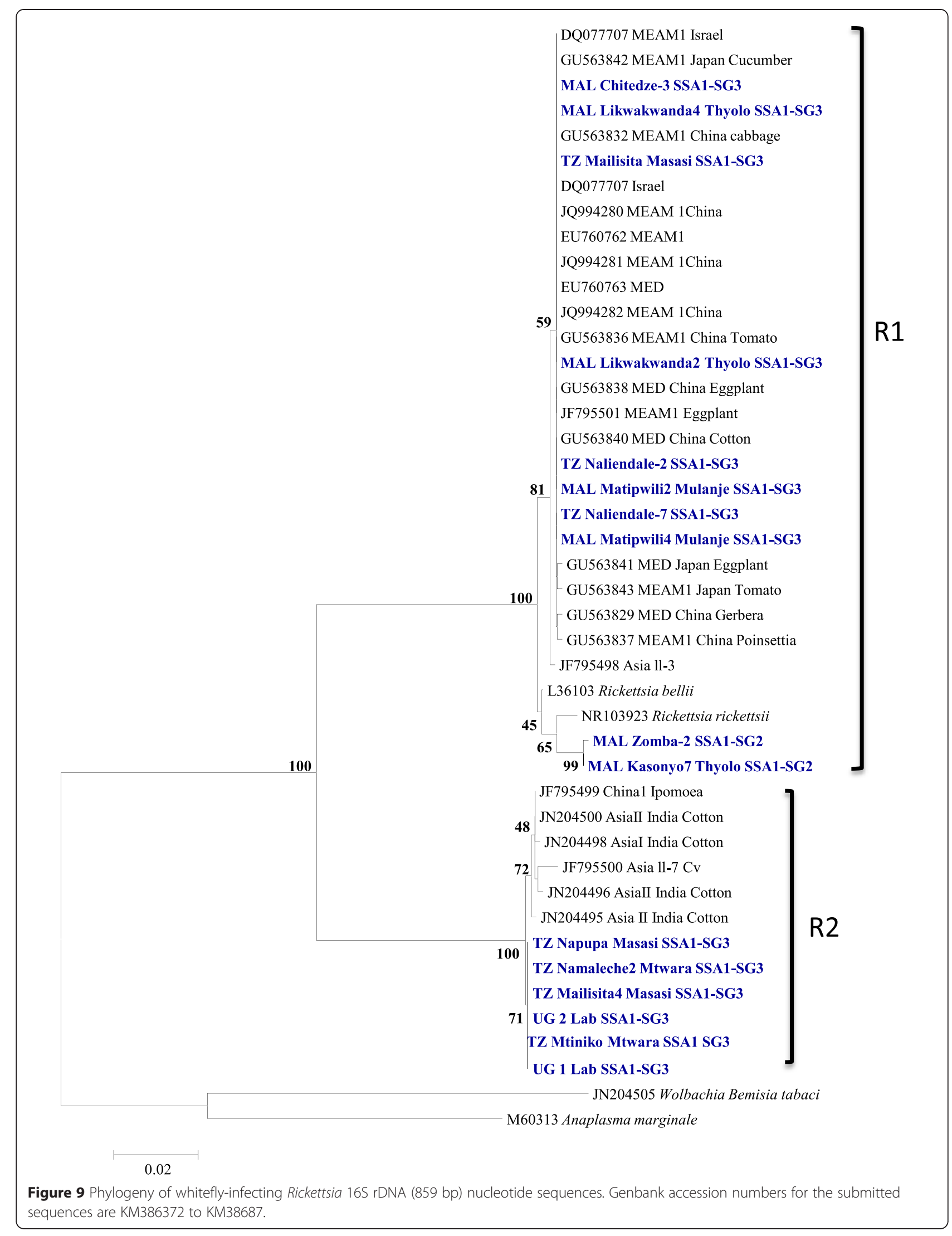


Table 4 Percentage nucleotide identities of 16S rDNA sequences of Rickettsia strains (p-distances were calculated using MEGA 5.0)

\begin{tabular}{|c|c|c|c|c|c|c|c|c|c|c|c|c|c|c|c|c|c|c|}
\hline TZ_Mailisita-2_SSA1-SG3 & & & & & & & & & & & & & & & & & & \\
\hline TZ_Naliendale-7_SSA1-SG3 & 100 & & & & & & & & & & & & & & & & & \\
\hline MAL_Chitedze-3_SSA1-SG3 & 100 & 100 & & & & & & & & & & & & & & & & \\
\hline MAL_Zomba-2_SSA1-SG2 & 98.4 & 98.4 & 98.4 & & & & & & & & & & & & & & & \\
\hline MAL_Kasonyo-7_SSA1-SG2 & 98.5 & 98.5 & 98.5 & 99.9 & & & & & & & & & & & & & & \\
\hline DQ077707_MEAM1_Israel & 100 & 100 & 100 & 98.4 & 98.5 & & & & & & & & & & & & & \\
\hline JQ994281_MEAM1_China & 100 & 100 & 100 & 98.4 & 98.5 & 100 & & & & & & & & & & & & \\
\hline EU760763_MED & 100 & 100 & 100 & 98.4 & 98.5 & 100 & 100 & & & & & & & & & & & \\
\hline L36103_Rickettsia_bellii & 99.5 & 99.5 & 99.5 & 98.8 & 99.0 & 99.5 & 99.5 & 99.5 & & & & & & & & & & \\
\hline NR103923_R_rickettsii & 98.5 & 98.5 & 98.5 & 99.0 & 99.1 & 98.5 & 98.5 & 98.5 & 99 & & & & & & & & & \\
\hline JN204498_Asia_I_India & 91.5 & 91.5 & 91.5 & 90.6 & 90.8 & 91.5 & 91.5 & 91.5 & 91.5 & 91.2 & & & & & & & & \\
\hline JN204495_Asia_II_India & 91.6 & 91.6 & 91.6 & 90.8 & 90.9 & 91.6 & 91.6 & 91.6 & 91.6 & 91.3 & 99.8 & & & & & & & \\
\hline JF795498_Asia_II_3 & 99.9 & 99.9 & 99.9 & 98.3 & 98.4 & 99.9 & 99.9 & 99.9 & 99.4 & 98.4 & 91.6 & 91.7 & & & & & & \\
\hline JF795500_Asia_II_7 & 91.1 & 91.1 & 91.1 & 90.3 & 90.4 & 91.1 & 91.1 & 91.1 & 91.1 & 90.9 & 99.4 & 99.4 & 91.2 & & & & & \\
\hline JF795499_China1 & 91.5 & 91.5 & 91.5 & 90.6 & 90.8 & 91.5 & 91.5 & 91.5 & 91.5 & 91.2 & 99.8 & 99.8 & 91.6 & 99.4 & & & & \\
\hline UG2_Lab_strain_SSA1-SG3 & 91.5 & 91.5 & 91.5 & 90.9 & 91.0 & 91.5 & 91.5 & 91.5 & 91.5 & 91.5 & 99.5 & 99.5 & 91.6 & 99.2 & 99.8 & & & \\
\hline TZ_Mtiniko_SSA1-SG3 & 91.5 & 91.5 & 91.5 & 90.9 & 91.0 & 91.5 & 91.5 & 91.5 & 91.5 & 91.5 & 99.5 & 99.5 & 91.6 & 99.2 & 99.8 & 100 & & \\
\hline TZ_Namaleche-2_SSA1-SG3 & 91.3 & 91.3 & 91.3 & 90.8 & 90.9 & 91.3 & 91.3 & 91.3 & 91.3 & 91.3 & 99.4 & 99.4 & 91.5 & 99.1 & 99.7 & 99.9 & 99.9 & \\
\hline TZ_Napupa_SSA1-SG3 & 90.9 & 90.9 & 90.9 & 90.3 & 90.4 & 90.9 & 90.9 & 90.9 & 90.9 & 90.9 & 98.7 & 98.7 & 91.0 & 98.4 & 99.0 & 99.2 & 99.2 & 99.1 \\
\hline
\end{tabular}

Overall, about $77.3 \%$ of cassava whiteflies were infected with at least one secondary symbiont, while the remaining $22.7 \%$ were completely free of the tested bacteria. These results were similar to the incidences of secondary symbionts seen in other B. tabaci, which ranged from $78 \%$ to $100 \%[14,30,35,36]$. A high percentage of the superabundant SSA1-SG1 from the CMD pandemic areas [32] and SSA1-SG5 whiteflies [37] were also reported to be free of secondary symbionts. Further studies comparing the fecundity and life cycle of bacteria-infected and uninfected cassava whiteflies is essential to understand the reasons behind the development of superabundant whiteflies, and the supposed interactions between symbionts and cassava whiteflies.

Single infections of bacteria were more prevalent (59\% of total infections) in cassava whiteflies than double (37\%) and triple (4\%) infections. This was slightly contrary to other studies in which co-infections were more common $(>60 \%)$ than single infections [14,36,32]. The reasons or the implications of this is unknown but could be due to competition for space and resources among the symbionts [38] or the tolerance of the host to harbour

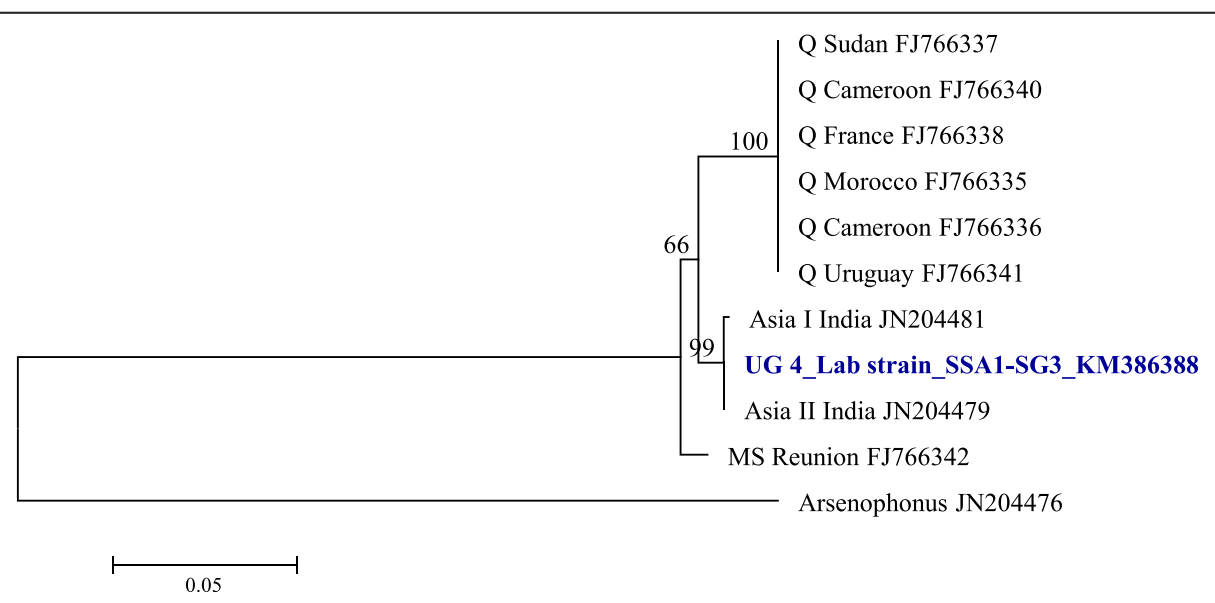

Figure 10 Phylogeny of Cardinium, based on the 165 rDNA sequences, infecting whiteflies around the world. 
many bacterial communities [35]. Although this is yet to be investigated thoroughly for cassava whiteflies, but specific interactions between bacterial strains and whitefly populations was clearly evident. For example, SSA1-SG1 and SSA1-SG2 were both infected with similar strains of Wolbachia, which were similar to those bacteria infecting butterflies and mosquitoes, whereas SSA1-SG3 was infected with a different Wolbachia. Infection levels of Rickettsia were highest in SSA1-SG3 (54\%), which was also similar to the invasive Rickettsia sp. nr Bellii strain that invaded the whitefly population MEAM1 in the USA with fitness benefits to the infected host [17]. However, infection with the same strain of Rickettsia in MEAM1 populations from Israel had no selective advantage to the host [39] and this further indicates specific interaction between symbiont and host genotype or the environment. When and how the Rickettsia invaded cassava whiteflies is unknown, but it remains to be seen if they also provide fitness benefits or not on cassava plants. Another puzzle in the jigsaw of whitefly-bacterial interactions was the detection of three different strains of Arsenophonus in cassava whiteflies. Strain A3 in particular was highly divergent, $7 \%$ nucleotide differences, compared to other Arsenophonus infecting B. tabaci across the world. A3 is closely related to the male killing Arsenophonus nasoniae [40], which again might influence the population dynamics and remains the focus of our future investigations. In summary, our findings provide insights to the diverse bacterial species infecting cassava whiteflies in African countries, and that these should be considered in future studies aiming to better understand the changing population dynamics in African cassava fields.

\section{Conclusions}

Genetically diverse bacteria infect cassava whiteflies in Africa and their prevalence varied across the different whitefly populations and geographies. Optimising the diagnostic protocols and the characterisation of endosymbionts infecting cassava whiteflies will be highly useful for future investigations on the role of the bacteria on whitefly biology, population development and virus transmission.

\section{Methods}

Whitefly sampling and populations studied

Adult whiteflies collected on cassava plants in four countries; Tanzania, Uganda, Malawi and Nigeria (Table 5) and preserved in alcohol were used in diversity studies. Two laboratory populations of cassava whiteflies originally collected from Uganda and Tanzania [26] and were subsequently maintained on cassava plants in insectary conditions $\left(27 \pm 5^{\circ} \mathrm{C}, 60 \%\right.$ relative humidity and L12:D12). These were used for detecting endosymbionts and studying their genetic diversity.

\section{Detection and molecular characterisation of endosymbionts}

Total DNA was extracted from individual adult whiteflies using the Chelex method [41] with slight modifications. Each whitefly was ground in $100 \mu \mathrm{l}$ TE solution (10 mM Tris- $\mathrm{HCl}$ and $1 \mathrm{mM}$ EDTA, $\mathrm{pH}$ 8.0) containing 20\% Chelex (BIO-RAD, UK) and $300 \mu \mathrm{g}$ Proteinase K. Samples were incubated at $60^{\circ} \mathrm{C}$ for 1.5 hours followed by protein denaturation at $96^{\circ} \mathrm{C}$ for 10 minutes. Samples were then centrifuged at $13,000 \mathrm{rpm}$ and the supernatant

Table 5 Collection sites of whitefly samples from cassava fields in Africa

\begin{tabular}{llll}
\hline Country & District (Locations) & Date collected & Number of whiteflies tested \\
\hline Tanzania & Mtwara district (Mtiniko, Namaleche) & November, 2012 & 10 \\
Tanzania & Masasi district (Napupa, Mailisita, Mnolela) & January, 2014 & 10 \\
Malawi & Thyolo district (Kasonyo, Likwakwanda) & November, 2012 & 15 \\
Malawi & Mulanje district (Matipwili) & January, 2014 & 8 \\
Malawi & Lilongwe district (Chitedze) & January, 2014 & 13 \\
Malawi & Salima district (Chitala) & January, 2014 & 10 \\
Uganda & Masaka district (Masaka) & November, 2013 & 47 \\
Uganda & Wakiso district (Wakiso) & October, 2012 & 51 \\
Nigeria & Oyo state (Ibadan, Kajode, Ajibode, Mokola) & October, 2012 & 43 \\
Nigeria & Imo state (Egbu) & September, 2012 & 10 \\
Nigeria & Abia state (Umuahia) & October, 2012 & 15 \\
Uganda & Namulonge (Laboratory population) & October, 2012 & -- \\
Tanzania & Dar-es-Salaam (Laboratory population) & 1997 & -- \\
\hline
\end{tabular}


was collected and stored at $-20^{\circ} \mathrm{C}$. Whitefly mtCOI genes and the endosymbiont $16 \mathrm{~S}$ or $23 \mathrm{~S}$ rDNA were amplified by polymerase chain reactions (PCR) using genus specific primers (see Additional file 1). New primers were designed for Cardinium and Wolbachia to increase efficiency and specificity of detection. Multilocus sequence typing (MLST) based on the diversity of five conserved housekeeping genes; $c o x A, f b p A, f t s Z$, gat $B$ and $h c p A$ have been used as a standard tool for strain typing and evolutionary studies of Wolbachia. The MLST approach was used to characterize the Wolbachia infecting cassava whiteflies using standard primers and protocols [42]. The Wolbachia surface protein (wsp) gene was also used as an additional marker for characterisation. Amplification of these genes was carried out in $25 \mu \mathrm{l}$ volumes using $2 \mu \mathrm{l}$ DNA lysate as template, $0.4 \mu \mathrm{M}$ of each primer, $0.15 \mathrm{mM}$ of dNTPs, $1 \times$ DreamTaq Green buffer and 0.5 unit DreamTaq Green DNA polymerase (Thermo Scientific Ltd., UK). Amplifications consisted of $94^{\circ} \mathrm{C}$ for 3 minutes followed by 38 cycles of $94^{\circ} \mathrm{C}$ for 30 seconds, annealing for 45 seconds (Additional file 1: Table S1), $72^{\circ} \mathrm{C}$ for 1.5 minutes and final extension for 7 minutes at $72^{\circ} \mathrm{C}$. PCR products were visualised on $1 \%$ agarose gels containing RedSafe nucleic acid staining solution (Intron Biotechnology, Korea). PCR products were purified and submitted for Sanger sequencing (Source Bioscience, UK) in both directions per whitefly sample, and five samples were sequenced for each location. Endosymbionts were also detected and sequences from two laboratory whitefly strains (Table 5). Sequences were compared to known sequences in databases using the BLAST algorithm in NCBI.

\section{Developing a diagnostic tool for cassava whiteflies}

The mtCOI fragments from five whitefly samples per location were sequenced, followed by phylogenetic analysis with reference sequences of haplotypes [6] for the identification of consensus haplotype groupings. The whitefly mtCOI sequences generated were analysed to identify unique restriction endonuclease sites using the software package NEBcutter (http://tools.neb.com/NEBcutter2). Three enzymes Bgl II (A/GATCT), Apo I (R/AATTY) and Dde I (C/TNAG) were found to produce unique patterns across SSA populations. The mtCOI fragments were re-amplified from at least 20 adults for each cassava whitefly population using $3 \mu \mathrm{l}$ of DNA template and 1 unit of DreamTaq DNA polymerase in $30 \mu \mathrm{l}$ volume reactions (40 cycles) for higher yields. Previously extracted DNA from four SSA2 whitefly samples were used in this assay as reference samples [26]. The RFLP was carried out in a two-step procedure. First, $15 \mu \mathrm{l}$ of PCR products were digested with 5 units of $B g l$ II. Second, the remaining $15 \mu \mathrm{l}$ of PCR products were digested with 5 units each of Apo I and Dde I at $37^{\circ} \mathrm{C}$ for 1.5 hours. Digested products were electrophoresed separately on $2 \%$ agarose gels.

\section{Phylogenetic and statistical analysis}

The mtCOI sequences from the whitefly, the $16 \mathrm{~S}$ or $23 \mathrm{~S}$ rDNA sequences from the endosymbionts and the MLST sequences from Wolbachia were aligned separately using ClustalW of MEGA 5.2 [43]. Phylogenetic trees were constructed by the maximum-likelihood method using MEGA 5.2. Different nucleotide substitution models were used based on the lowest Bayesian information criterion scores obtained. Phylogenetic trees for mtCOI and Wolbachia were generated using the T93+G+I substitution model, the $\mathrm{HKY}+\mathrm{G}$ substitution model for Arsenophonus, the $\mathrm{K} 2+\mathrm{G}$ substitution model for Rickettsia and the K2 substitution model for Cardinium [44]. The robustness of the clades was assessed by 1000 bootstrap replicates.

The probabilities of bacterial infections in cassava whitefly populations were predicted using simple binomial logistic regression. Each bacterium was used as the dependent variable and the whitefly populations as independent variables. Differences in infection patterns among groups were evaluated by Tukey's HSD test using the glht function from multcomp package of $\mathrm{R}$ [45].

\section{Availability of supporting data}

The data sets supporting the results of this article are available in the MLST and EMBL database with unique sequence and accession numbers. These are currently publicly available.

Genbank accession numbers generated in this study are as below; mtCOI sequences KM377899 to KM377952, and KM407138 to KM407141; Wolbachia wsp KP208705 to KP208733; Arsenophonus 23S rDNA KM377863 to KM377898, Rickettsia 16S rDNA.

KM386372 to KM38687; and Cardinium KM386388. The accession number for the MLST sequence types on the pubMLST database for the Wolbachia infecting cassava whitefly are 423-425 and 427.

\section{Additional file}

Additional file 1: Table S1. Primer sequences and annealing temperatures used for PCR amplification. Table S2. Multiple comparisons of mean infection incidence of symbionts: Tukey contrasts.

Competing interests

The authors declare that they have no competing interests.

\section{Authors' contributions}

MNM conceived the work, designed research, collected samples and corrected the paper extensively. SB helped with analysis and corrected the paper. SG designed and performed research, carried out most of the analysis and made initial draft of the paper. All authors read and approved the final manuscript. 


\section{Authors' information}

Saptarshi Ghosh is a PhD student at the Natural Resources Institute, University of Greenwich, UK.

Sophie Bouvaine is a Research Fellow at the Natural Resources Institute, University of Greenwich, UK.

M. N. Maruthi, who is commonly known as Maruthi M. N. Gowda is a Reader in Molecular Plant Pathology at the Natural Resources Institute, University of Greenwich, UK.

\section{Acknowledgements}

Part of this work was funded by the Bill and Melinda Gates Foundation as part of the Grand Challenges Explorations Grant (Number OPP1060099) awarded to the Natural Resources Institute. We thank Gerald Otti, Geoffrey Mkamillo, Ibrahim Benesi and Peter Wasswa for their cooperation in collecting whitefly samples in the fields. SG received a scholarship from the University of Greenwich for his PhD.

\section{Received: 24 November 2014 Accepted: 15 April 2015}

\section{Published online: 02 May 2015}

\section{References}

1. Jones DR. Plant viruses transmitted by whiteflies. Eur J Plant Path. 2003;(109):195-219.

2. De Barro PJ, Liu SS, Boykin LM, Dinsdale AB. Bemisia tabaci: a statement of species status. Ann Rev Entomol. 2011:56:1-19.

3. Dinsdale A, Cook L, Riginos C, Buckley YM, De Barro P. Refined global analysis of Bemisia tabaci (Hemiptera: Sternorrhyncha: Aleyrodoidea: Aleyrodidae) mitochondrial cytochrome oxidase 1 to identify species level genetic boundaries. Ann Entomol Soc Am. 2010;103:196-208.

4. Brown JK. Phylogenetic biology of the Bemisia tabaci sibling species group In: Stansley PA, Naranjo SE, editors. Bemisia: bionomics and management of a global pest. Dordrecht-Heidelberg-London-New York: Springer; 2010. p. 31-67.

5. Legg JP, Fauquet CM. Cassava viruses in Africa. Plant Mol Biol. 2004;56:585-99.

6. Legg JP, Sseruwagi P, Boniface S, Okao-Okuja G, Shirima R, Bigirimana S, et al. Spatio-temporal patterns of genetic change amongst populations of cassava Bemisia tabaci whiteflies driving virus pandemics in East and Central Africa. Virus Res. 2013;186:61-75.

7. Legg JP, French R, Rogan D, Okao-Okuja G, Brown JK. A distinct Bemisia tabaci (Gennadius) (Hemiptera: Sternorrhyncha: Aleyrodidae) genotype cluster is associated with the epidemic of severe cassava mosaic virus disease in Uganda. Mol Ecol. 2002;11:1219-29.

8. Legg JP, Owor B, Sseruwagi P, Ndunguru J. Cassava mosaic virus disease in East and Central Africa: epidemiology and management of a regional pandemic. Adv Virus Res. 2006;67:355-418.

9. Simón B, Cenis JL, De La Rúa P. Distribution patterns of the Q and B biotypes of Bemisia tabaci in the mediterranean basin based on microsatellite variation. Entomol Exp Appl. 2007:124:327-36.

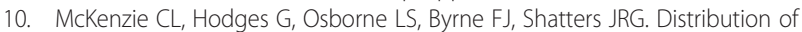
Bemisia tabaci (Hemiptera: Aleyrodidae) biotypes in Florida-investigating the Q invasion. J Econ Entomol. 2009;102:670-6.

11. Pan H, Chu D, Ge D, Wang S, Wu Q, Xie W, et al. Further spread of and domination by Bemisia tabaci (Hemiptera: Aleyrodidae) biotype $\mathrm{Q}$ on field crops. China J Econ Entomol. 2011;104:978-85.

12. Zchori-Fein E, Brown JK. Diversity of prokaryotes associated with Bemisia tabaci (Gennadius) (Hemiptera: Aleyrodidae). Ann Entomol Soc Am. 2002:95:711-8.

13. Ahmed MZ, Ren S, Xue X, Li XX, Jin G, Qiu BL. Prevalence of endosymbionts in Bemisia tabaci populations and their in vivo sensitivity to antibiotics. Curr Microbiol. 2010;61:322-8

14. Gueguen G, Vavre F, Gnankine O, Peterschmitt M, Charif D, Chiel E, et al. Endosymbiont metacommunities, mtDNA diversity and the evolution of the Bemisia tabaci (Hemiptera: Aleyrodidae) species complex. Mol Ecol. 2010;19:4365-78.

15. Bing XL, Yang J, Zchori-Fein E, Wang XW, Liu SS. Characterization of a newly discovered symbiont of the whitefly Bemisia tabaci (Hemiptera: Aleyrodidae). Appl Environ Microb. 2013;79:569-75.

16. Werren JH, Baldo L, Clark ME. Wolbachia: master manipulators of invertebrate biology. Nat Rev Microbiol. 2008;6:741-51.
17. Himler AG, Adachi-Hagimori T, Bergen JE, Kozuch A, Kelly SE, Tabashnik BE, et al. Rapid spread of a bacterial symbiont in an invasive whitefly is driven by fitness benefits and female bias. Science. 2011;332:254-6.

18. Brumin M, Kontsedalov S, Ghanim M. Rickettsia influences thermotolerance in the whitefly Bemisia tabaci B biotype. Insect Sci. 2011;18:57-66.

19. Hendry TA, Hunter MS, Baltrus DA. The facultative symbiont Rickettsia protects an invasive whitefly against entomopathogenic Pseudomonas syringae strains. Appl Env Microb. 2014;80:7161-8.

20. Kontsedalov S, Zchori-Fein E, Chiel E, Gottlieb Y, Inbar M, Ghanim M. The presence of Rickettsia is associated with increased susceptibility of Bemisia tabaci (Homoptera: Aleyrodidae) to insecticides. Pest Manag Sci. 2008;64:789-92.

21. Everett KDE, Thao M, Horn M, Dyszynski GE, Baumann P. Novel chlamydiae in whiteflies and scale insects: endosymbionts "Candidatus Fritschea bemisiae" strain Falk and "Candidatus Fritschea eriococci" strain Elm. Int J Syst Evol Micr. 2005;55:1581-7.

22. Gottlieb Y, Zchori-Fein E, Mozes-Daube N, Kontsedalov S, Skaljac M, Brumin $M$, et al. The transmission efficiency of tomato yellow leaf curl virus by the whitefly Bemisia tabaci is correlated with the presence of a specific symbiotic bacterium species. J Virol. 2010;84:9310-7.

23. Rana VS, Singh ST, Priya NG, Kumar J, Rajagopal R. Arsenophonus GroEL interacts with CLCuV and is localized in midgut and salivary gland of whitefly B. tabaci. PLoS One. 2012;7, e42168.

24. Su Q, Pan H, Liu B, Chu D, Xie W, Wu Q, et al. Insect symbiont facilitates vector acquisition, retention, and transmission of plant virus. Sci Rep. 2013;3:1367

25. Kliot A, Cilia M, Czosnek H, Ghanim M. Infection of the whitefly Bemisia tabaci with Rickettsia spp. alters its interactions with Tomato yellow leaf curl virus. J Virol. 2014:88:5652-60.

26. Maruthi MN, Colvin J, Seal S. Mating compatibility, life-history traits, and RAPD-PCR variation in Bemisia tabaci associated with the cassava mosaic disease pandemic in East Africa. Entomol Exp Appl. 2001;99:13-23.

27. Sseruwagi P, Maruthi MN, Colvin J, Rey MEC, Brown JK, Legg JP. Colonisation of non-cassava plant species by cassava whiteflies (Bemisia tabaci) (Gennadius) (Hemiptera:Aleyrodidae) in Uganda. Entomol Exp Appl. 2006;119:145-53.

28. Berry SD, Fondong V, Rey C, Rogan D, Fauquet CM, Brown JK. Molecular evidence for five distinct Bemisia tabaci (Homoptera:Aleyrodidae) geographic haplotypes associated with cassava in sub-Saharan Africa. Ann Entomol Soc Am. 2004;97:852-9.

29. Tajebe LS, Boni SB, Guastella D, Cavalieri V, Lund OS, Rugumamu CP, et al. Abundance, diversity and geographic distribution of cassava mosaic disease pandemic-associated Bemisia tabaci in Tanzania. J Appl Entomol. 2014 (on-line version) doi:10.1111/jen.12197.

30. Bing X, Ruan Y, Rao Q, Wang X, Liu S. Diversity of secondary endosymbionts among different putative species of the whitefly Bemisia tabaci. Insect Sci. 2013;20:194-206

31. Singh ST, Priya NG, Kumar J, Rana VS, Ellango R, Joshi A, et al. Diversity and phylogenetic analysis of endosymbiotic bacteria from field caught Bemisia tabaci from different locations of North India based on 16S rDNA library screening. Infect Genet Evol. 2012;12:411-9.

32. Tajebe LS, Guastella D, Cavalieri V, Kelly SE, Hunter MS, Lund OS, et al. Diversity of symbiotic bacteria associated with Bemisia tabaci (Homoptera: Aleyrodidae) in cassava mosaic disease pandemic areas of Tanzania. Ann Appl Biol. 2014;166:297-310.

33. Augustinos AA, Santos-Garcia D, Dionyssopoulou E, Moreira M, Papapanagiotou A, Scarvelakis M, et al. Detection and characterization of Wolbachia infections in natural populations of aphids: is the hidden diversity fully unravelled? PLoS One. 2011;6, e28695.

34. Bing XL, Xia WQ, Gui JD, Yan GH, Wang XW, Liu SS. Diversity and evolution of the Wolbachia endosymbionts of Bemisia (Hemiptera: Aleyrodidae) whiteflies. Ecol Evol. 2014;4:2714-37.

35. Skaljac M, Zanic K, Ban SG, Kontsedalov S, Ghanim M. Co-infection and localization of secondary symbionts in two whitefly species. BMC Microbiol. 2010;10:142

36. Chiel E, Gottlieb Y, Zchori-Fein E, Mozes Daube N, Katzir N, Inbar M, et al. Biotype-dependent secondary symbiont communities in sympatric populations of Bemisia tabaci. B Entomol Res. 2007;97:407-13.

37. Gnankine O, Mouton L, Henri H, Terraz G, Houndete T, Martin T, et al. Distribution of Bemisia tabaci (Homoptera: Aleyrodidae) biotypes and their 
associated symbiotic bacteria on host plants in West Africa. Insect Conserv Divers. 2013;2013(6):411-21.

38. Vautrin E, Vavre F. Interactions between vertically transmitted symbionts: coperation or conflict? Trends Microbiol. 2009;17:95-9.

39. Chiel E, Inbar M, Mozes-Daube N, White JA, Hunter MS, Zchori-Fein E. Assessments of fitness effects by the facultative symbiont Rickettsia in the sweetpotato whitefly (Hemiptera: Aleyrodidae). Ann Entomol Soc Am. 2009;102:413-8.

40. Gherna RL, Werren JH, Weisburg W, Cote R, Woese CR, Mandelco L, et al. NOTES: Arsenophonus nasoniae gen. nov., sp. nov., the causative agent of the son-killer trait in the parasitic wasp Nasonia vitripennis. Int J Syst Bacteriol. 1991;41:563-5.

41. Walsh PS, Metzger DA, Higuchi R. Chelex 100 as a medium for simple extraction of DNA for PCR-based typing from forensic material. Biotechniques. 1991;10:506-13.

42. Baldo L, Dunning Hotopp JC, Jolley KA, Bordenstein SR, Biber SA, Choudhury RR, et al. Multilocus sequence typing system for the endosymbiont Wolbachia pipientis. Appl Env Microb. 2006;72:7098-110.

43. Tamura K, Peterson D, Peterson N, Stecher G, Nei M, Kumar S. MEGA5: molecular evolutionary genetics analysis using maximum likelihood, evolutionary distance, and maximum parsimony methods. Mol Biol Evol. 2011;28:2731-9.

44. Posada D. Selecting models of evolution. In: The phylogenetic handbook. A practical approach to DNA and protein phylogeny. Cambridge: Cambridge University Press; 2003. p. 256-82.

45. R Development Core Team. R:a language and environment for statistical computing. Vienna, Austria: R Foundation for Statistical Computing; 2011. http://www.R-project.org

\section{Submit your next manuscript to BioMed Central and take full advantage of:}

- Convenient online submission

- Thorough peer review

- No space constraints or color figure charges

- Immediate publication on acceptance

- Inclusion in PubMed, CAS, Scopus and Google Scholar

- Research which is freely available for redistribution 